\title{
El Cordobazo dibujado: "Invasión" política y experimentación gráfica
}

\author{
Laura Vázquez (Universidad de Buenos Aires) \\ Recibido: 25/09/09 \\ Aceptado: 30/10/09
}

RESUMEN: El objetivo de este artículo es re-colocar un objeto que en la actualidad acusa rasgos paradigmáticos. La hipótesis es que si bien las historietas se organizan en lo que podría denominarse "la cultura de masas occidental", al mismo tiempo, son permeables a desvíos que permiten problematizar esos límites. A partir de un caso se dará cuenta de la porosidad entre la política y la vanguardia, entre la cultura de masas y el arte. Se trata de abrir incomodidades y preguntarse por los intersticios. ¿Entre el arte y el activismo, la experimentación y la militancia, hay deslindes?

Palabras clave: Cordobazo / Historieta política / Política argentina /medios gráficos / vanguardia

\section{The drawn "Cordobazo": political "invasión" and graphic experimentation}

SUMMARY: The purpose of this article is to relocate an object that, nowadays, attributes paradigmatic features. The hypothesis is as follows: even though comic stripes are organized like "occidental mass-culture", their course is also prone to be altered in a way that those limits can be changed. Taken an specific case, the porosity between vanguard and politics and, also, art and massculture, will be exposed. We should be able to ask ourselves: Between art and activism, militance and experimentation, is there anything to clarify?

Key words: Cordobazo / political comic strip / Argentinian politics / graphic media / vanguard 


\section{Revoluciones de tinta china}

o es novedad sostener que el
Cordobazo ha sido interpretado desde múltiples (y aun distantes) perspectivas. Y se sabe que los medios visuales y gráficos (la fotografía, el cine, la televisión, la prensa) han sido fuentes fundamentales para analizar el acontecimiento y abrir líneas de abordaje que permitieran comprender la significación del acontecimiento y reconstruir el suceso. Sin embargo, si bien ciertas "imágenes masivas" capturadas por la cámara y por la prensa han tenido un peso fundamental en la investigación sobre el Cordobazo, el papel de otros medios y lenguajes (e incluso su modo de producción, circulación y consumo) permanece inexplorado como línea de trabajo. Entonces, partiendo de la premisa de que las imágenes son vehículos privilegiados para registrar el pasado y hacer inteligible la experiencia, este artículo busca explorar de qué manera el acontecimiento del Cordobazo es re-presentado en las páginas de una historieta masiva.

Precisamente, la ubicuidad del lenguaje historietístico ${ }^{1}$ permite reponer el sentido, al menos, en dos niveles. Por un lado, rompe la jerarquía según la cual la escritura se considera superior a la imagen al poner en tensión la oposición palabra/imagen, por otro lado, la producción historietística abreva de dos saberes que, lejos de estar categóricamente separados, se entrelazan en las prácticas de representación y producción: el campo artístico y el profesional, el arte y el mercado. De allí que desde la historia cultural y las artes visuales, estas páginas buscan ampliar el diálogo con los trabajos existentes, a la vez que pretenden sistematizar una fuente gráfica y narrativa que ha permanecido opaca frente a otras series documentales, con el objetivo de plantear interrogantes sobre la materialidad de las imágenes y su recepción masiva.

Paradojas del mundo gráfico: el mismo día que arranca el Cordobazo, en la ficción historietística un grupo de amigos acaba su partida de truco al oír una transmisión radial que anuncia la caída de una nevada. ${ }^{2}$ La comunicación se interrumpe varias veces, hasta que el Comandante en Jefe Provisional informa que Sudamérica ha

1 He trabajado este tema en mi tesis doctoral "Oficio, arte y mercado. Historia de la historieta argentina 1968-1984" (Universidad de Buenos Aires, Facultad de Ciencias Sociales, 2009). Desde esta línea de análisis, la singularidad del lenguaje historietístico propone una apertura y un cruce productivo entre el campo artístico y el profesional, el arte y el mercado, el registro de la imagen en otros soportes y la representación e interpretación ficcional de esas evocaciones y saberes.

2 La segunda versión de El Eternauta se publica desde el número 201 (29/5/69) hasta el número 217 (18/9/69) de la revista Gente, dividida en diecisiete entregas de tres páginas 
sido entregada al invasor. A diferencia de su versión original de 1957, esta vez el héroe épico deja paso a una figura inscrita en el complejo entramado político. Este remake de El Eternauta, publicada en la revista Gente, permite reflexionar sobre las tensiones entre industria cultural, política y vanguardia artística. Pero también hace posible visualizar de qué manera las imágenes fotográficas, fílmicas y de prensa son reelaboradas para reconstruir ficcionalmente un hecho histórico.

Asimismo, esta serie - censurada por la editorial Atlántida - da cuenta de que la irrupción del Cordobazo hace virar radicalmente la visión del guionista Héctor Oesterheld (la cuestión ya no pasaba por encontrar un régimen político que permitiera la más amplia participación sino por invertir las relaciones de fuerza en pos de la transferencia del poder) al mismo tiempo que abre canales para reflexionar sobre la viabilidad de una vanguardia de masas.

A finales de la década de 1960, la historia de Juan Salvo había circulado por distintas ediciones y Oesterheld había hecho de las historias de ciencia ficción el leitmotiv de su narrativa. Al estar vinculada a la versión de 1957, recoloca el pasado y vuelve visible su experiencia, al mismo tiempo que actualiza el presente más inmediato. De allí que pueda afirmarse que funciona a la manera de una constelación imprecisa de sentidos, una "estructura de sentimiento" o zona caracterizada por su dinámica e indefinición (Williams 2000). La versión de 1969 evidencia la adhesión de Oesterheld a la "cultura de izquierda" (Altamirano 2001) y la maduración de una gráfica de avanzada en el trazo de Alberto Breccia. $^{3}$

Ahora bien, el hecho de que se repusiera una historieta producida doce años atrás propone un doble interrogante: ¿por qué Oesterheld y Breccia realizan una historieta ya arcaica para Gente y por qué la revista la publicó? Intentemos aproximarnos a una explicación posible. En el contexto de finales de los años sesenta, $E l$ Eternauta ya constituía un material legitimado y, en cierto modo, canoni-

semanales y por un período consecutivo de cuatro meses. Por indicaciones editoriales, lo que no es sino una forma de censura, los autores debieron "acelerar" los últimos episodios para que la historieta no fuera levantada de su publicación. De allí que es difícil contrastar la trama de esta edición con la de su versión original, debido a que escenas y capítulos claves de aquella están ausentes en la de 1969.

3 Sin embargo, la matriz narrativa de esta historieta siguió aferrada a la versión original; asociada al imaginario tecnológico de las revistas de divulgación científica y técnica de las primeras décadas del siglo. En tal sentido, la historieta se mueve "a dos aguas", entre lo "emergente" y lo "residual" del género. 
zado, por distintos espacios, sobre todo por circuitos ajenos al campo de la producción historietística. En ese contexto, la serie atrajo a algunos sectores artísticos e intelectuales. ${ }^{4} \mathrm{La}$ decisión de editar la historieta más exitosa del mercado local puede articularse con el impulso modernizador de la época y con la búsqueda de cierta "actualidad", de la que Gente se propone como referente:

A no sorprenderse que le traemos el cuento o el dibujo fácil. Hemos pensado muy bien el caso y terminamos por decidirnos por éste -para nosotrosnuevo idioma, porque lo consideramos el apropiado para llevar al lector, en toda su fuerza, la creación de los autores, a quienes hemos pedido una "historieta para adultos" con toda la explosión imaginativa (en el guión y en el dibujo) con que puedan encarnar un tema muy de hoy: EL ETERNAUTA. [...] Dentro de una semana comenzaremos la publicación de la historieta. Y será el comienzo de una nueva manera de comunicarnos. Usted y nosotros.

Se trata de una historieta atemporal en el tratamiento ficcional y con- temporánea en su proyección de los acontecimientos políticos. El imaginario científico técnico es el mismo en la historia original y en su adaptación, pero la visión política cambia radicalmente en esta última. Cabe pensar entonces que se trató de una "cuestión de prioridades": ¿qué era lo urgente para Oesterheld en 1969? En la trama está presente la idea de que el futuro no debía descansar en el mito moderno del progreso, sino en la acción política y la revolución social. De ahí que no haya reformulado ningún tópico del género y sí, en cambio, la psicología y las acciones de sus personajes.

Obviamente, la invasión extraterrestre oesterheldiana enlaza con las abundantes invasiones que prosperan en los medios masivos de la época. Pero esta vez la premisa argumental es diferente. De ese afuera no llega "algo positivo" o auspicioso. La historia connota el temor del mundo capitalista de posguerra a ser conquistado, por ese "otro" que no estaba en las estrellas, sino en la ideología comunista de la Unión Soviética. Pero a diferencia de la literatura y la cinematografía norteamericanas del periodo, el texto de Oesterheld coexiste con la

4 Pocos meses antes de que circulara en Gente, y en el contexto de la Bienal Mundial de la Historieta celebrada en el Di Tella, una empresa de producción de comerciales (Gil \& Bertolini) obtiene los derechos del personaje con la idea de concretar un proyecto de dibujos animados para televisión. El proyecto se canceló por motivos económicos y solo se llegó a realizar un capítulo piloto. Se anunció su estreno en el marco de la Bienal de la Historieta: "El Eternauta, que posiblemente compita en la Bienal [...] tratándose de una experiencia nueva en cortos, puede resultar una realización positiva" (Revista 2001 2, 1968). 
agenda política, en la que se repudia al imperialismo y se consolida la idea de una revolución tercermundista. En la historieta de 1969, el anuncio radial es radicalmente opuesto al de su versión original:

Comandante en Jefe Provisional... Nevada Mortífera... vasta zona latinoamericana... despiadado ataque extraterrestre... traición inconcebible grandes potencias. Sudamérica entregada al invasor para salvarse... lucharemos igual... por más solos que estemos y por terrible que haya sido el golpe inicial, sobrevivientes en la emergencia... sacrificio.

Es ostensible el modo como se resalta - con una tipografía gruesa y negra - el comunicado de los militares detallado más arriba. La técnica del dibujante apuesta a los negros y a los blancos planos y uniformes, a la iluminación con efecto de contraste y a recursos plásticos como el collage y los raspados. Los violentos claroscuros en el trazo "torturado" de Breccia dan lugar a una atmósfera estremecedora, acompañando la visión pesimista y contrariada del narrador. El experimentalismo gráfico participa en la tarea de volver legible la historia y, al mismo tiempo, la reconceptualiza por medio de la búsqueda del significado del texto. Son viñetas que transmiten un halo de opresión y represión pero también permiten leer la resistencia de los cuerpos, la subversión política. En definitiva, y en tanto documento de época, los dibujos del combate en
Buenos Aires entre los sobrevivientes de la nevada y un enemigo extraterrestre, pueden contrastarse con las escenas de enfrentamiento en las calles de la ciudad Córdoba; ficción e historia otra vez se enlazan en una forma específica de comunicación de sentido.

Por otra parte, en la versión de 1969, la nevada deja de aparecer como una catástrofe tecno-científica, para pasar a ser la consecuencia lógica de un sistema opresivo. En este contexto, el rol que juegan las Fuerzas Armadas cambia bruscamente. A diferencia de la de 1957, en la que el Ejército funciona como promotor de la resistencia popular, en la remake el militar a cargo del operativo, ordena: "necesitamos ya mismo todos los voluntarios que podamos juntar. $\mathrm{i}$ salen en tres minutos o les baleamos las ventanas!". Pocos episodios después es fusilado un civil solo porque disiente de la opinión del capitán. Es evidente que la visión de los militares es otra en este contexto. La perplejidad de Juan Salvo se evidencia cada vez que Favalli, pura racionalidad política y estrategia, intenta hacerle comprender los "nuevos tiempos políticos":

- Los grandes países para no ser atacados les entregaron Sudamérica.

- ¿Sudamérica?

- Sí Juan, toda Sudamérica será el territorio de los invasores. Empezaron la conquista atacando con la nevada a las ciudades, es una guerra total de exterminio. 
La versión de Gente, a diferencia de la clásica, genera fuertes polémicas en el medio historietístico y en el interior de la publicación. Durante la tercera entrega de la serie, además de dedicarle espacios considerables a la muerte de Vandor, a la visita de Rockefeller y a la vida de la modelo María Larreta, Gente publica una editorial titulada: "Que el ruido no nos aturda". Mientras tanto, las cartas de lectores aluden al dibujo como "no historietístico" o "demasiado artísti$\mathrm{CO}^{\prime \prime}$ y no se insinúan siquiera los cambios políticos de la trama. En todos los casos, las cartas se ofrecen como testimonios irrefutables del curso desacertado que siguió la serie. A medida que avanzan las entregas, las cartas se vuelven más críticas con el dibujo experimental de la historieta.

Sin embargo, el trabajo de Breccia antes que carecer de "sentido historietístico" como afirma un "decepcionado" y "antiguo lector de El Eternau$t a "$, define un estilo de avanzada. Precisamente, la virtud de este remake es el de ser un texto político que, al mismo tiempo, no renuncia a la experimentación gráfica y estética. Una señora que pide dibujos "menos artísticos y más claros", dirigidos "a gente más normal", o el lector que se queja de la "intelectualización" del dibujante, no hacen más que evidenciar que la relación que mantiene el autor con su obra es siempre una relación mediatizada. ${ }^{5}$

Ahora bien, el director de Gente, Carlos Fontanarrosa, desde Nueva York, se dirige a los lectores mediante una carta. Esta se publica bajo el título: "Ojos argentinos... y sorprendidos". Tras dedicar párrafos extensos a la exaltación del cine norteamericano y a criticar el nacional, porque "juega con la forma y se queda en la superficie", Fontanarrosa explica las causas de su desengaño con la serie intentando justificar su desenlace abrupto:

Que me disculpe Breccia, un gran dibujante y diría artista, pero nosotros en nuestra misión de lograr comunicación no debíamos habernos entregado a la forma estética de su dibujo, que por momentos la hizo ininteligible. Aquí también la forma, el adorno,

5 Por otro lado, puede interpretarse que no se trató de una cuestión de "competencias artísticas". Durante las primeras entregas se puede constatar que varios lectores halagan el trazo del dibujante y están lejos de desmerecer su estilo gráfico. Asimismo, si interpretamos la editorial como "un pedido de disculpas" por ofrecer a sus lectores un "producto decepcionante", nos preguntamos cómo es que se podía desconocer el trabajo de los autores si la misma empresa los había convocado. Aunque no podemos dar cuenta de las condiciones de recepción de esta obra, es curioso el dato de que mientras en el momento de su publicación en Gente la reedición fue despreciada por su experimentalismo, fue este rasgo el que resultó de interés para sus editores internacionales. 
el medio, se convirtió en fin y quedó a mitad de camino nuestra intención. Me vino a la cabeza esta autocrítica, porque cuando veo una cosa bien hecha, directa, firme, que va al nudo del asunto y abandona florilegios y pequeñeces para llegar, me entusiasma. [...] les pido algo más: corrijan las faltas de sintaxis y si hay algo muy exagerado también, pero déjenle el tono familiar, eufórico, porque equivocado o no, las cosas las he sentido así (Gente 216, 18 de octubre de 1969).

En el siguiente número, y mientras se anuncia en tapa la llegada del hombre a la Luna, la historia de la invasión ya no estaba entre sus páginas. Si la escena de la policía montada condensa un sentido político del Cordobazo, el análisis de esta historieta permite identificar también otros íconos: barricadas, fuego en las calles, colectivos, multitudes que corren, civiles armados, trajes improvisados, espacios urbanos reconocibles, autos volcados, carteles. Al igual que las imágenes televisivas, analizadas por Mirta Varela (2005), se trata de íconos que reduplican imágenes próximas en el tiempo en mayo de 1969.

Sin embargo, y a diferencia de la prensa diaria, de las imágenes televisivas y de las cinematográficas, la historieta en Gente supone un tratamiento del Cordobazo que está en las antípodas de las interpretaciones más habituales. Un momento heroico de la lucha política en los relatos de iz- quierda es presentado en la historieta desde otro lugar. Si bien se señala la inclusión de otros sectores sociales en la lucha y se describe metafóricamente el retroceso de la dictadura, las viñetas sobreimprimen a la barricada, la imaginería popular.

\section{Conclusiones: Imagen y política}

En este ensayo se trató de exponer las arterias ideológicas de un texto producido (y producto) de la industria cultural, con la convicción de que lo ideológico supone una dimensión estructurante de la subjetividad. Lo que produjeron los guionistas y los dibujantes en las historietas publicadas durante la dictadura militar y durante la transición democrática, aquello que contaron en sus páginas, puede explicarnos algo acerca de la cultura y la sociedad.

Como vimos, a finales de los sesenta el trabajo conjunto del guionista argentino y del uruguayo Alberto Breccia da cuenta de una producción atípica en el campo de las artes visuales, a la vez que permite problematizar ciertos temas centrales de la etapa: politización, modernización y vanguardia. La posición de estos autores en el mercado de la historieta argentina, y aún latinoamericana, da cuenta de un cruce singular y productivo entre arte, cultura de masas y política e instala una discusión acerca del papel que asume (o debería asumir) el 
intelectual en distintas coyunturas históricas. ${ }^{6}$ A la manera de un programa visual transformador, componen una matriz en la que la exaltación revolucionaria se vuelve no solo inevitable, sino su única razón de ser; y la paradoja es que lo hacen el espacio conservador de una revista de interés general en contubernio explícito con el régimen imperante.

Por lo tanto, este trabajo tomó como eje de análisis un fragmento de la producción historietística de los autores realizada a finales de la década de 1960 en un intento por reubicar la tensión entre imagen y política. A partir de la complejización del modelo de intelectual y del artista de época, cuyo grado de autonomía respecto de lo político se vio fuertemente alterado, producciones como las de Oesterheld y Breccia permiten pensar en la articulación posible entre experimentación estética y radicalización política. En otros términos: si en las vanguardias de principios de siglo había primado la fuerza revulsiva, creativa e interventora del arte como sustrato ideológico, durante los años sesenta se ponía en juego su propio significado.

La historieta es política porque no puede velar sus mecanismos de enunciación, su cadena de montaje sígnica se nos hace evidente una y otra vez: la narrativa en secuencia gráfica presenta y representa en sus viñetas las formas conscientes de una determinada visión del mundo. En sus gramáticas de producción esas sustracciones, desvíos y ambigüedades (elipsis, metáforas, metonimias, estilos, usos de los colores y entintados, líneas, grafías, disposición de globos y viñetas, etcétera) pueden ocurrir saltos insolentes, ejercicios de lectura sorprendentemente inesperados.

En ocasiones, el potencial subversivo del lenguaje historietístico se presenta bajo la forma de un inocente sarcasmo. Y por esas ironías de la historia algunas de sus versiones (subterráneas y subrepticias respecto de otras producciones masivas) pueden obsequiarnos, aun sin quererlo, un relato alternativo en el seno mismo de la industria.

6 Desde el famoso caso Dreyfus, en adelante, y en tanto "mito de origen", la cuestión de los intelectuales ha nutrido las reflexiones de diferentes escuelas y perspectivas. El concepto intelectual no es una categoría circunscripta a un período determinado ni permite derivar funciones ontológicas o una definición normativa capaz de prescribir la práctica intelectual. Por el contrario, su uso ofrece el legado de una discusión teórica compleja, que despierta diversas apropiaciones, modelos y formas de jerarquizar las áreas de su intervención. Este artículo se separa de la definición universal de intelectual. Sigo, en cambio, la crítica que Raymond Williams dirige a esa acepción clásica (véase Williams, 2000). 


\section{Bibliografía}

Altamirano, C. (2001). Peronismo y cultura de izquierda. Buenos Aires: Récord.

Bailo, V. y D. Stefanelli (directores) (1998). H.G.O. Documental. Argentina.

Feld, Cl. y J. Stites Mor (comps.) (2009). El pasado que miramos. Memoria e imagen ante la historia reciente. Buenos Aires: Paidós.
LIPSZYC, E. y O. MASOTTA (comp.) (1968). Catálogo de la Primera Bienal Mundial de la Historieta. Buenos Aires: Instituto Torcuato Di Tella.

Saccomanno, G. y C. Trillo (1980). Historia de la historieta argentina. Buenos Aires: Récord.

VARELA, M. (2005). La televisión criolla. Desde sus inicios hasta la llegada del hombre a la Luna. 1951-1969. Buenos Aires: Edhasa.

Williams, R. (2000). Marxismo y literatura. Barcelona: Península. 